\title{
Ovarian cancer-derived lysophosphatidic acid stimulates secretion of VEGF and stromal cell-derived factor-1 $\alpha$ from human mesenchymal stem cells
}

\author{
Eun Su Jeon ${ }^{1,3_{*}}$, Soon Chul Heo ${ }^{1,2 *}$, II Hwan Lee ${ }^{1,2}$, \\ Yoon Ji Choi ${ }^{1,2}$, Ji Hye Park ${ }^{1,2}$, Kyung Un Choi ${ }^{3}$, \\ Do Youn Park ${ }^{3}$, Dong-Soo Suh ${ }^{4}$, Man-Soo Yoon ${ }^{4}$ \\ and Jae Ho Kim ${ }^{1,2,5}$ \\ ${ }^{1}$ Medical Research Center for Ischemic Tissue Regeneration \\ Medical Research Institute \\ ${ }^{2}$ Department of Physiology \\ ${ }^{3}$ Department of Pathology \\ ${ }^{4}$ Department of Obstetrics and Gynecology \\ School of Medicine, Pusan National University \\ Yangsan 626-870, Korea \\ ${ }^{5}$ Corresponding author: Tel, 82-51-510-8073; \\ Fax, 82-51-510-8076; E-mail, jhkimst@ pusan.ac.kr \\ *These authors contributed equally to this work. \\ DOI 10.3858/emm.2010.42.4.027
}

Accepted 4 February 2010

Available Online 22 February 2010

Abbreviations: CAFs, carcinoma-associated fibroblasts; CM, conditioned medium; hASCs, human adipose tissue-derived mesenchymal stem cells; HUVECs, human umbilical vein endothelial cells; LPA, lysophosphatidic acid; MRTF, myocardin-related transcription factor; MSCs, mesenchymal stem cells; SDF-1, stromal cell-derived factor-1; shRNA, small hairpin RNA; SMCs, smooth muscle cells; SRF, serum response factor; $\alpha$-SMA, $\alpha$-smooth muscle actin

\begin{abstract}
Lysophosphatidic acid (LPA) stimulates growth and invasion of ovarian cancer cells and tumor angiogenesis. Cancer-derived LPA induces differentiation of human adipose tissue-derived mesenchymal stem cells (hASCs) to $\alpha$-smooth muscle actin ( $\alpha$-SMA)-positive cancer-associated fibroblasts. Presently, we explored whether cancer-derived LPA regulates secretion of pro-angiogenic factors from hASCs. Conditioned medium (CM) from the OVCAR-3 and SKOV3 ovarian cancer cell lines stimulated secretion angiogenic factors such as stromal-derived factor-1 $\alpha$ (SDF-1 $\alpha$ ) and VEGF from hASCs. Pretreatment with the LPA receptor inhibitor Ki16425 or short hairpin RNA lentiviral silencing of the $L A_{1}$ receptor abrogated the cancer CM-stimulated expression of $\alpha$-SMA, SDF-1, and VEGF from hASCs. LPA induced expression of myocardin
\end{abstract}

and myocardin-related transcription factor-A, transcription factors involved in smooth muscle differentiation, in hASCs. siRNA-mediated depletion of endogenous myocardin and MRTF-A abrogated the expression of $\alpha$-SMA, but not SDF-1 and VEGF. LPA activated RhoA in hASCs and pretreatment with the Rho kinase inhibitor Y27632 completely abrogated the LPA-induced expression of $\alpha$-SMA, SDF-1, and VEGF in hASCs. Moreover, LPA-induced $\alpha$-SMA expression was abrogated by treatment with the ERK inhibitor U0126 or the phosphoinositide-3-kinase inhibitor LY294002, but not the PLC inhibitor U73122. LPA-induced VEGF secretion was inhibited by LY294002, whereas LPA-induced SDF-1 secretion was markedly attenuated by U0126, U73122, and LY294002. These results suggest that cancer-secreted LPA induces differentiation of hASCs to cancer-associated fibroblasts through multiple signaling pathways involving Rho kinase, ERK, PLC, and phosphoinositide-3-kinase.

Keywords: carcinoma; fibroblasts; lysophosphatidic acid; ovarian neoplasms; receptors, lysophosphatidic acid; rho-associated kinases; vascular endothelial growth factor $A$

\section{Introduction}

Tumors are composed of genetically altered malignant cells along with a heterogenous population of non-neoplastic stromal cell components, such as fibroblasts, myofibroblasts, endothelial cells, pericytes, and inflammatory cells, and tumor cells interact with the stromal cells via paracrine signaling (De Wever and Mareel, 2003). Carcinoma-associated fibroblasts (CAFs, also called as myofibroblasts or cancer stroma), which express $\alpha$-smooth muscle actin ( $\alpha$-SMA), play important roles during cancer progression and metastasis (Bhowmick et al., 2004; Desmouliere et al., 2004; Orimo and Weinberg, 2006; De Wever et al., 2008). They stimulate tumorigenesis, angiogenesis, and invasion in a variety of solid tumors, including prostate, breast, and ovarian carcinomas (Sappino et al., 1988; Olumi et al., 1999; De Wever and Mareel, 2003; Orimo et al., 2005; Ganss, 2006) by secreting various extracellular matrix 
proteins, proteases, chemokines, and angiogenic factors (Li et al., 2007).

Mesenchymal stem cells (MSCs) have a self-renewal capacity, long-term viability, and differentiation potential toward diverse cell types that include adipogenic, osteogenic, chondrogenic, and myogenic lineages (Prockop, 1997; Pittenger et al., 1999; Short et al., 2003; Barry and Murphy, 2004). MSCs are distributed throughout various tissues, and so may be local sources of tissue-resident stem cells (Crisan et al., 2008). Moreover, MSCs are recruited into the stroma of developing tumors (Hall et al., 2007) and constitute a large proportion of non-neoplastic stromal cells within the tumor microenvironment (De Wever et al., 2008). Accumulating evidence suggests that MSCs could also have an adverse effect that favors tumor growth. When transplanted together with tumor cells, MSCs stimulate capability of proliferation of tumor cells and enhance angiogenesis in tumor tissues (Zhu et al., 2006). Furthermore, MSCs stimulate metastatic potency of breast carcinoma when coinjected with human breast carcinoma cells into a subcutaneous site by xenograft transplantation (Karnoub et al., 2007). Human bone marrow-derived MSCs exposed to tumor-conditioned medium (CM) exhibit phenotypic and functional characteristics of CAFs including sustained expression of $\alpha$-SMA and stromal-derived factor-1 (SDF-1), a pro-angiogenic chemokine, and the ability to promote tumor cell growth in vitro and in an in vivo coimplantation model (Mishra et al., 2008). Furthermore, it has been reported that VEGF secreted from MSCs induce sprouting of human umbilical vein endothelial cells (HUVECs) in vitro and stimulate in vivo tumor angiogenesis in a pancreatic carcinoma model (Beckermann et al., 2008). These observations suggest that CAFs differentiated from MSCs plays a key role in the tumorigenesis and angiogenesis through production of SDF-1 and VEGF.

Lysophosphatidic acid (LPA) is a small bioactive phospholipid produced by activated platelets, mesothelial cells, fibroblasts, adipocytes, and some cancer cells (Gaits et al., 1997; Mills and Moolenaar, 2003; Aoki, 2004). Accumulating evidence suggests that LPA is relevant to tumorigenesis and metastasis by stimulating proliferation, survival, migration, and invasion of cancer cells (Mills and Moolenaar, 2003). The biological functions of LPA are mediated through LPA receptors (Anliker and Chun, 2004; Moolenaar et al., 2004; Tabata et al., 2007; Murakami et al., 2008). Activation of LPA receptors mediates the biological responses through activating multiple signaling pathways involving PLC, ERK, phosphatidylinositol-3-kinase, and Rho kinase (Mills and Moolenaar, 2003; Birgbauer and Chun, 2006). We have previously reported that LPA induces migration of human adipose tissue-derived MSCs (hASCs) and stimulates expression of $\alpha$-SMA and SDF-1 in vitro (Jeon et al., 2008a; Lee et al., 2008), suggesting a pivotal role of LPA in the generation of CAFs within the tumor microenvironment. LPA-induced expression of $\alpha-S M A$ is dependent on activation of an autocrine TGF- $\beta 1$ signaling loop, whereas the stimulatory effect of LPA on SDF-1 expression is mediated in part by TGF- $\beta 1$ (Jeon et al., 2008a). Therefore, it is still unclear whether cancer-derived LPA can regulate expression of not only $\alpha$-SMA and SDF-1, but also VEGF. Moreover, the molecular mechanisms by which LPA induces expression of $\alpha-S M A$, SDF-1, and VEGF in hASCs remain elusive.

An increasing body of evidence supports the idea that $\alpha$-SMA expression is regulated by serum response factor (SRF) and the myocardin family of SRF co-factors, i.e. myocardin, myocardin-related transcription factor-A (MRTF-A or MKL1), and myocardin-related transcription factor-B (MRTF-B or MKL2) (Owens et al., 2004; Pipes et al., 2006; Parmacek, 2007). SRF binds to the CArG boxes in the promoter of $\alpha-S M A$ and myocardin activates SRF-dependent transcription (Chen et al., 2002; Wang et al., 2002; Du et al., 2003; Yoshida et al., 2003). In unstimulated cells, MRTF-A/B are sequestered in the cytoplasm through direct interaction with G-actin, but RhoA-Rho kinase-mediated actin polymerization depletes the G-actin pool, which frees MRTF from G-actin to enter the nucleus where it can stimulate SRF-dependent transcription of $\alpha$-SMA (Miralles et al., 2003). Therefore, these results suggest that the RhoA-Rho kinase pathway plays a key role in the expression of $\alpha$-SMA by regulating the integrity of the cytoskeleton and the cellular locale of MRTF (Miano, 2003; Cen et al., 2004). However, the role of Rho kinase, myocardin, and MRTF in the LPA-induced expression of $\alpha$-SMA has not been explored.

In the present study, we explored whether ovarian cancer-derived LPA induces expression of $\alpha-S M A$, SDF-1, and VEGF, and characterized the signaling pathways involved in the LPA-induced gene expression.

\section{Results}

\section{CM from ovarian cancer cells stimulates secretion of angiogenic factors from hASCs}

In order to explore whether hASCs can regulate angiogenesis within tumor microenvironment, 
A

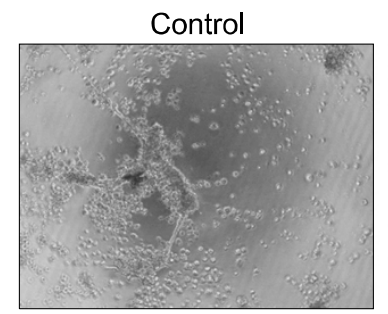

hASC CM

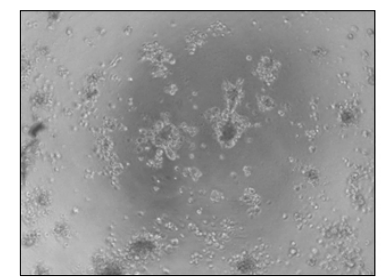

B

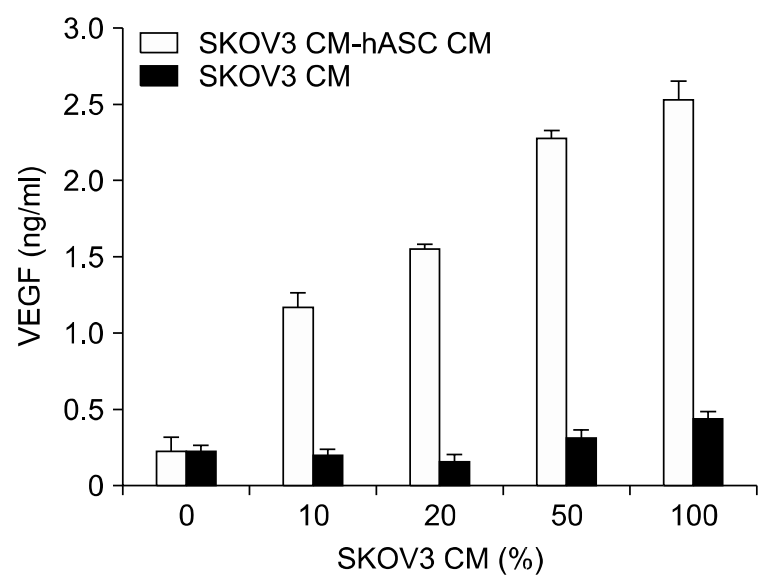

OVCAR3 CM

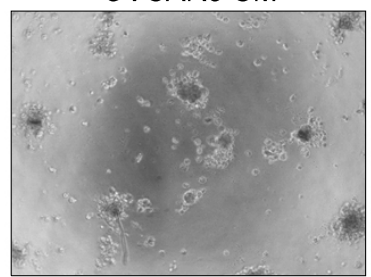

OVCAR3 CM-hASC CM
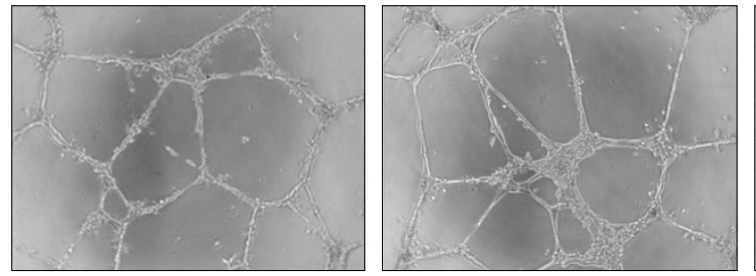

C

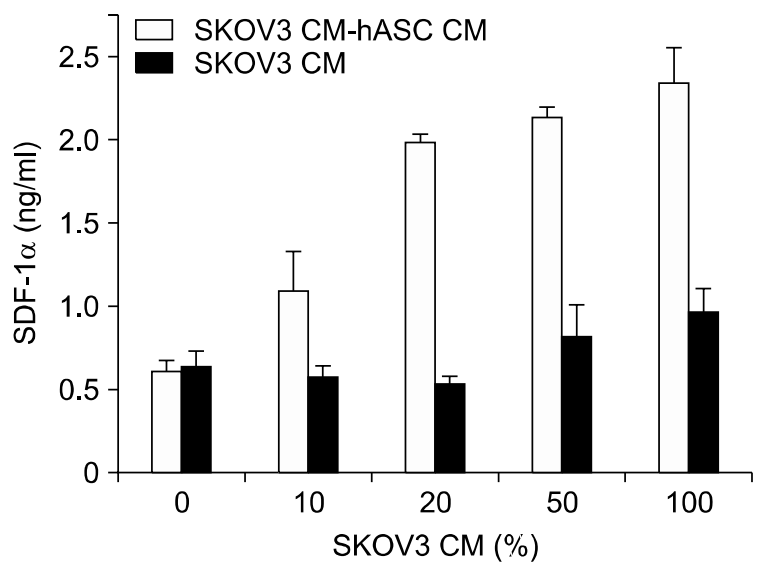

Figure 1. Cancer CM-induced secretion of VEGF and SDF-1 from hASCs. (A) hASCs were pretreated with SKOV3 CM, OVCAR3 CM, $5 \mu$ M LPA, or serum-free $\alpha$-MEM for $48 \mathrm{~h}$ for collection of SKOV3 CM-hASC CM, OVCAR3 CM-hASC CM, LPA-hASC CM, or hASC CM, respectively. HUVECs were plated onto a layer of Matrigel, and treated with the culture supernatants from hASCs for $12 \mathrm{~h}$. As control experiments, HUVECs were treated with $\alpha$-MEM (control), SKOV3 CM, OVCAR3 CM, or $5 \mu \mathrm{M}$ LPA for $12 \mathrm{~h}$. The images were photographed using an inverted microscope with a digital camera. (B and C) hASCs were treated with the indicated concentrations of SKOV3 CM for $48 \mathrm{~h}$ for collection of SKOV3 CM-hASC CM. The concentrations of VEGF (B) and SDF-1 (C) in SKOV3 CM-hASC CM or SKOV3 CM were determined by ELISA.

hASCs were treated with CM from two different ovarian cancer cell types (OVCAR3 and SKOV3 cells) and the effects of culture supernatants from hASCs on tube formation of HUVECs were determined. As shown in Figure $1 \mathrm{~A}$, culture supernatants of hASCs (OVCAR3 CM-hASC CM or SKOV3 CM-hASC CM), which were prepared by pretreatment of hASCs with OVCAR3 CM or SKOV3 CM, greatly stimulated tube formation of HUVECs. Furthermore, culture supernatant from LPA-treated hASCs (LPA-hASC CM) also stimulated tube formation of HUVECs, whereas culture supernatant from serum-starved hASCs (hASC $\mathrm{CM}$ ) had no significant impact on tube formation.
Moreover, exposure of HUVECs to OVCAR3 CM, SKOV3 CM, or LPA did not significantly influence tube formation. These results suggest that hASCs secrete pro-angiogenic factors in response to cancer CM or LPA. To explore whether cancer CM stimulates secretion of pro-angiogenic factors from hASCs, the protein levels of VEGF and SDF-1 in the culture supernatant from hASCs were determined using ELISA analysis. SKOV3 CM dose-dependently stimulated secretion of VEGF and SDF-1 from hASCs, whereas the endogenous levels of VEGF and SDF-1 included in SKOV3 CM were negligible compared to the levels in the culture supernatants of SKOV3 CM-treated hASCs 

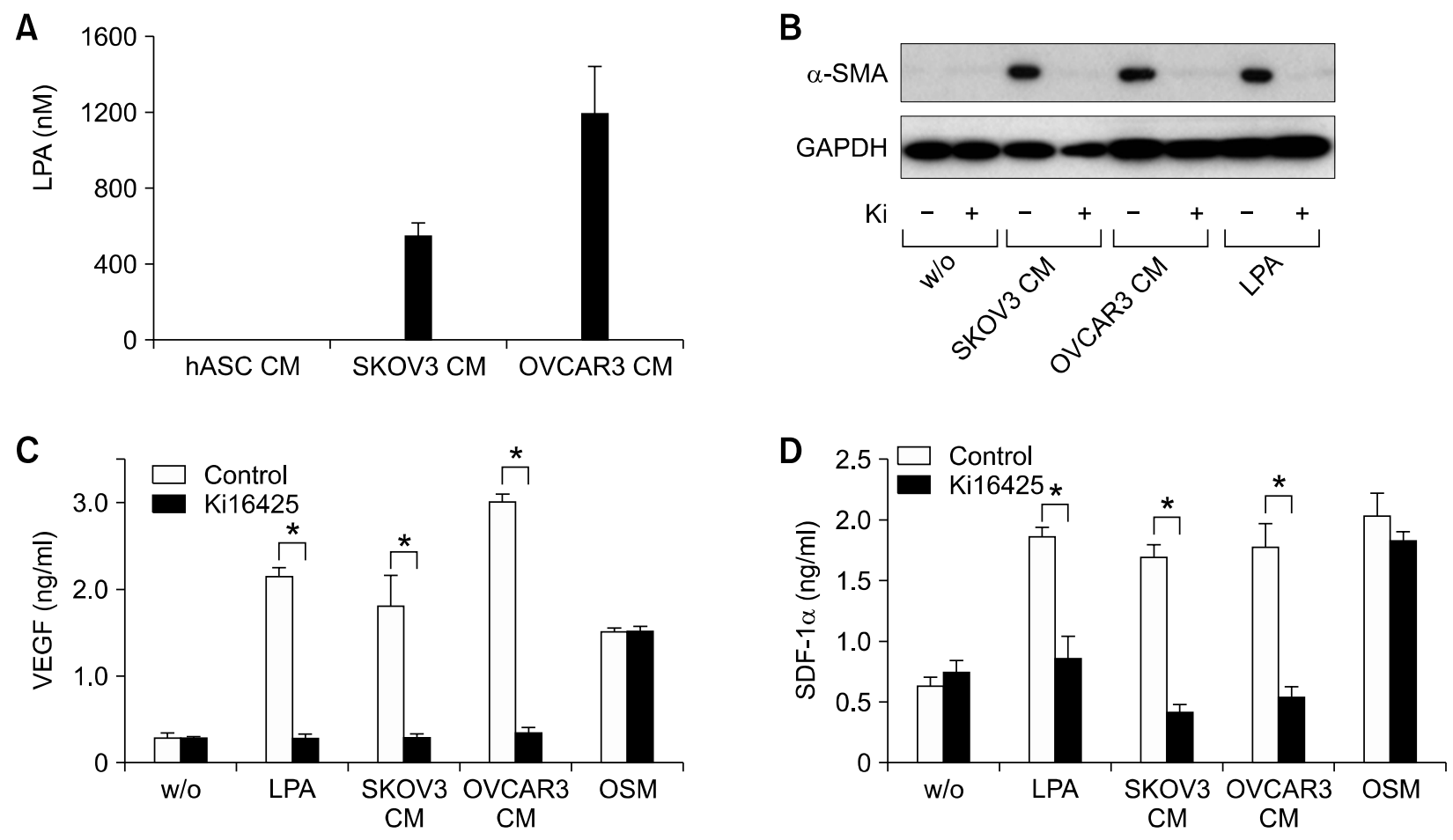

E
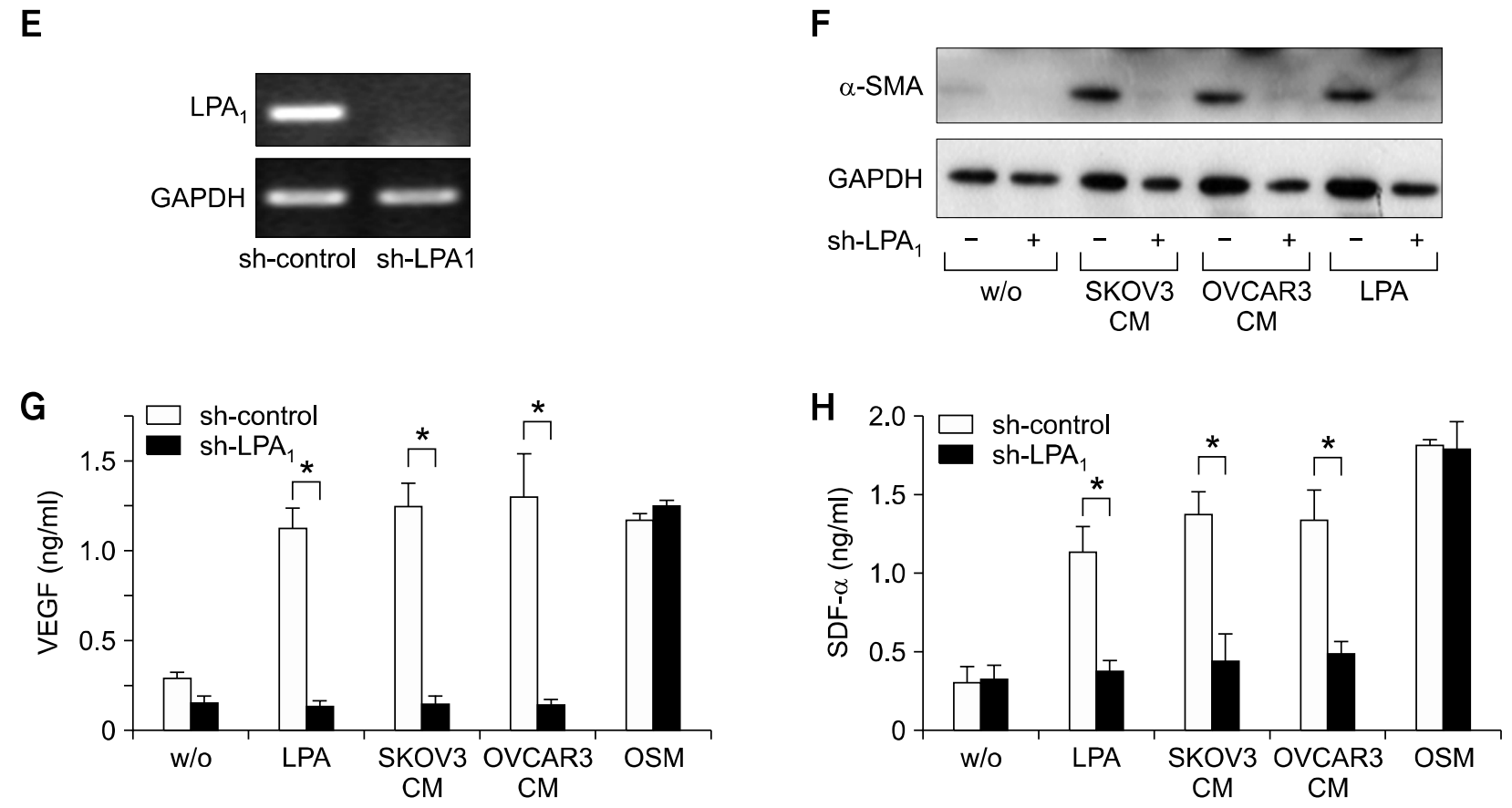

Figure 2. Role of LPA-LPA 1 signaling in the cancer CM-induced expression of $\alpha$-SMA, VEGF, and SDF-1. (A) Concentrations of LPA in CM from OVCAR3, SKOV3, and hASCs were determined. (B) Serum-starved hASCs were exposed to OVCAR3 CM, SKOV3 CM, or $5 \mu$ M 1-oleoyl-LPA in the presence or absence of $1 \mu \mathrm{M}$ Ki16425 for 4 days. The expression levels of $\alpha$-SMA and GAPDH were determined by Western blotting. (C-D) hASCs were treated with serum-free medium containing OVCAR3 CM, SKOV3 CM, $5 \alpha \mathrm{M}$ LPA or $10 \mathrm{ng} / \mathrm{ml}$ OSM in the presence or absence of $1 \alpha \mathrm{M}$ Ki16425 for $48 \mathrm{~h}$. (E) hASCs were infected with control (sh-control) or LPA (sh-LPA $_{1}$ ) shRNA lentivirus (pLKO.1-puro, MISSION, Sigma). After puromycin selection, the expression levels of $\mathrm{LPA}_{1}$ and GAPDH were determined by RT-PCR. (F) shRNA-infected cells were exposed to serum-free medium containing $5 \mu \mathrm{M}$ LPA, OVCAR3 CM or SKOV3 CM for 4 days and the expression levels of $\alpha$-SMA and GAPDH were determined by Western blotting. (G and H) hASCs were infected with control or LPA 1 shRNA lentivirus and treated with serum-free medium containing OVCAR3 CM, SKOV3 CM, $5 \mu$ M LPA or $10 \mathrm{ng} / \mathrm{ml}$ OSM for $48 \mathrm{~h}$. The secreted levels of VEGF and SDF-1 were determined by ELISA. Data represent mean \pm S.D. $(n=4) .{ }^{*}, P<0.01$ by two-way ANOVA and Scheffe's post hoc test. 

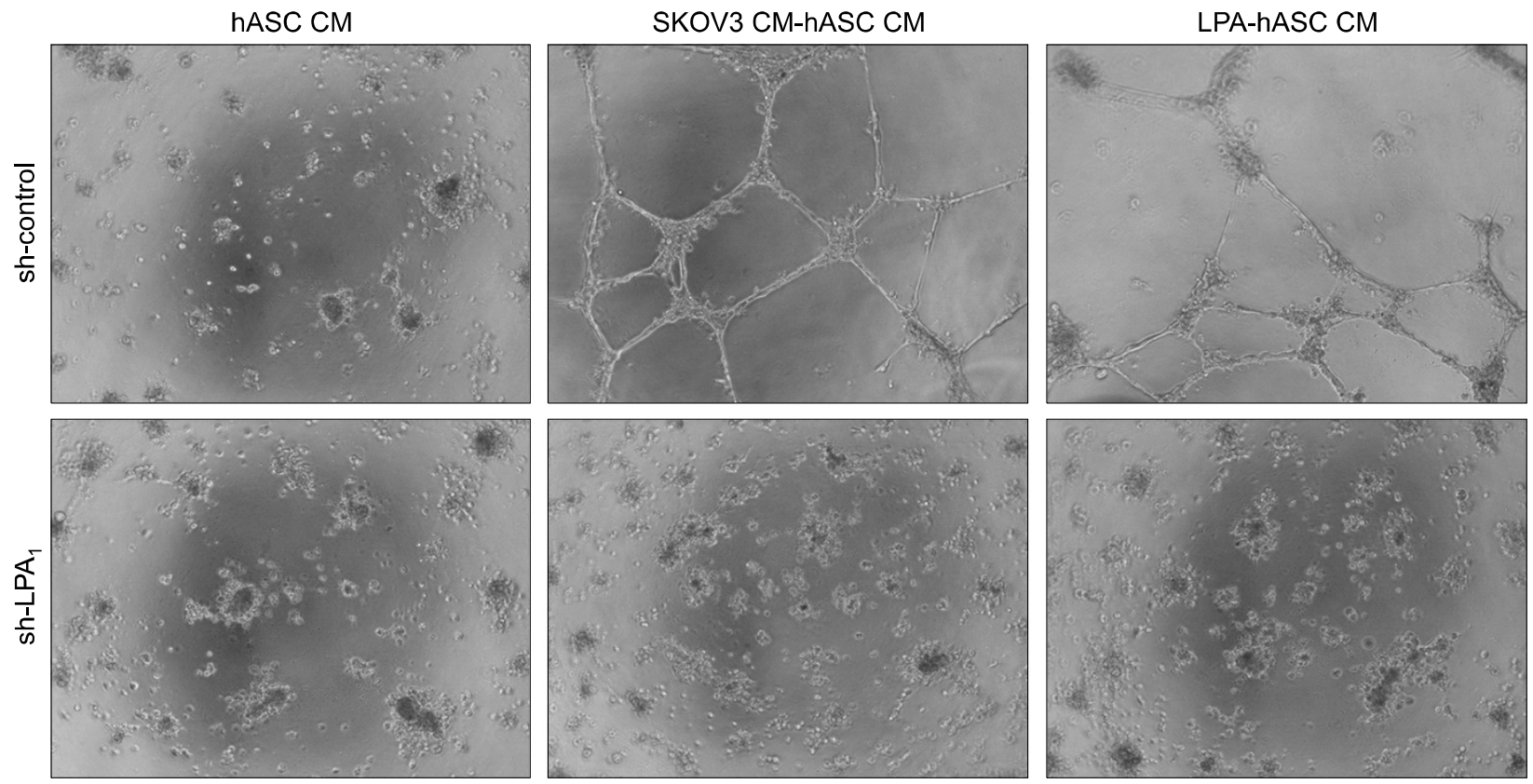

Figure 3. Role of $\mathrm{LPA}_{1}$ in the cancer CM stimulation of hASCs-mediated paracrine function on endothelial tube formation. hASCs were infected with sh-control or sh-LPA 1 lentivirus and then treated with SKOV3 CM, $5 \mu \mathrm{M} \mathrm{LPA}$, or serum-free $\alpha$-MEM for $48 \mathrm{~h}$ for collection of SKOV3 CM-hASC CM, LPA-hASC CM, or hASC CM, respectively. HUVECs were plated onto a layer of Matrigel, and treated with the conditioned medium from hASCs for $12 \mathrm{~h}$. The images were photographed using an inverted microscope with a digital camera. Representatives of three independent experiments are shown.

(Figures $1 \mathrm{~B}$ and $1 \mathrm{C})$. These results suggest that ovarian cancer cells stimulate secretion of VEGF and SDF-1 from hASCs through a paracrine mechanism.

\section{Role of $L P A-L P A_{1}$ receptor signaling pathway in cancer CM-induced expression of $\alpha$-SMA, SDF-1, and VEGF from hASCs}

In order to explore the role of LPA in the cancer CM-stimulated gene expression, we determined the concentrations of LPA in OVCAR3 CM and SKOV3 CM. As shown in Figure 2A, LPA was detected in the CM from OVCAR3 and SKOV3 cells, but not CM from serum-starved hASCs. The concentrations of LPA in OVCAR3 CM and SKOV3 $\mathrm{CM}$ were $1,193 \pm 245$ and $545 \pm 72 \mathrm{nM}$, respectively. Not only LPA but also CM from OVCAR3 and SKOV 3 cells induced expression of $\alpha$-SMA in hASCs, and the LPA receptor inhibitor Ki16425 abrogated the expression of $\alpha$-SMA induced by LPA or cancer CM (Figure 2B). To assess whether cancer CM-induced secretion of VEGF and SDF-1 was dependent on the LPA-LPA 1 signaling pathway, we determined the effects of Ki16425 on the levels of SDF-1 and VEGF secreted from hASCs. As shown in Figures 2C and 2D, LPA elicited secretion of VEGF and SDF-1 from hASCs in a Ki16425-sensitive manner. Furthermore, CM from
OVCAR3 or SKOV3 cells elicited secretion of VEGF and SDF-1 from hASCs, and cancer CM-induced secretion of VEGF and SDF-1 was abrogated by treatment with Ki16425. Oncostatin $M(O S M)$ has been reported to induce secretion of SDF-1 and VEGF from hASCs and adipocytes (Lee et al., 2007; Rega et al., 2007). OSM belongs to the interleukin (IL)- 6 family of cytokines and it acts on target cells by binding to a heterodimeric membrane receptor composed of the leukemia inhibitory factor- or OSM-specific receptor and the gp130 receptor chain (Gomez-Lechon, 1999). In contrast to the inhibitory effect of Ki16425 on the LPA-stimulated secretion of SDF-1 and VEGF, OSM-induced secretion of SDF-1 and VEGF was not affected by Ki16425 (Figures 2C and 2D).

To confirm the involvement of LPA receptors in the cancer $\mathrm{CM}$-induced expression of $\alpha$-SMA and angiogenic factors, we examined the effect of shRNA-mediated silencing of $\mathrm{LPA}_{1}$ expression. $L P A_{1}$ expression was down-regulated by lentiviral transduction of $\mathrm{LPA}_{1}$-specific shRNA (Figure $2 \mathrm{E}$ ). Depletion of endogenous $\mathrm{LPA}_{1}$ expression blocked the $\alpha$-SMA expression stimulated by LPA or cancer CM (Figure 2F), suggesting that the LPA-LPA ${ }_{1}$ signaling axis plays a key role in ovarian cancer CM-induced expression of $\alpha$-SMA in hASCs. We next clarified whether $\mathrm{LPA}_{1}$ was involved in the cancer CM-induced secretion of VEGF and SDF-1 
A

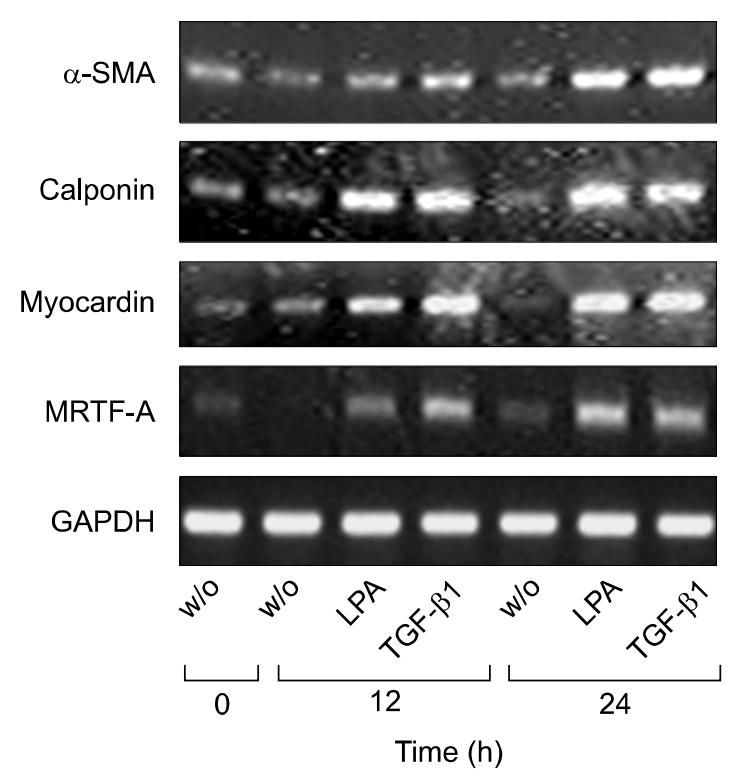

D

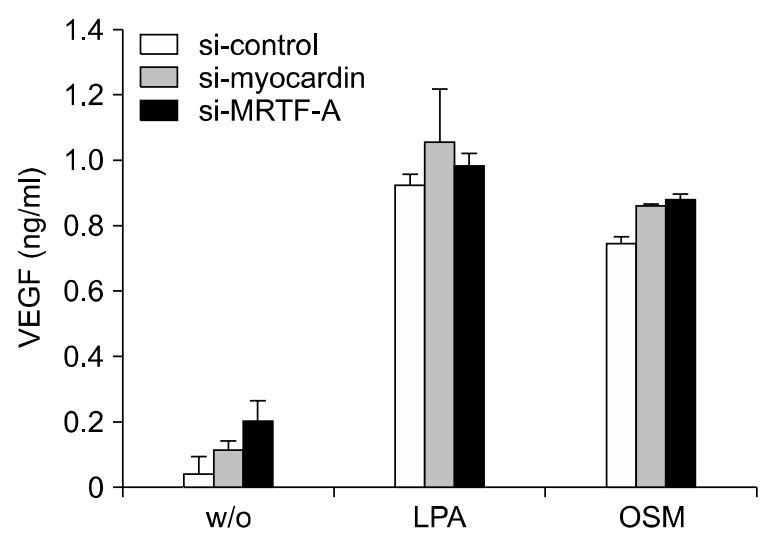

B

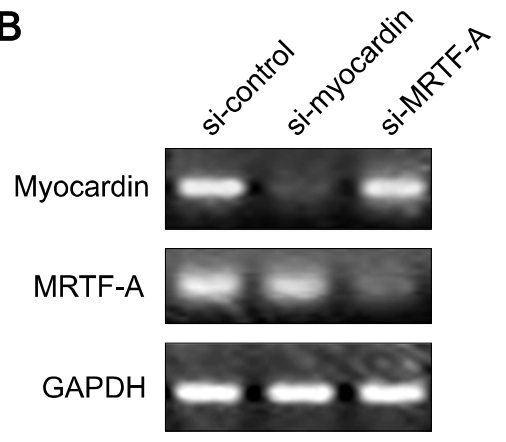

C

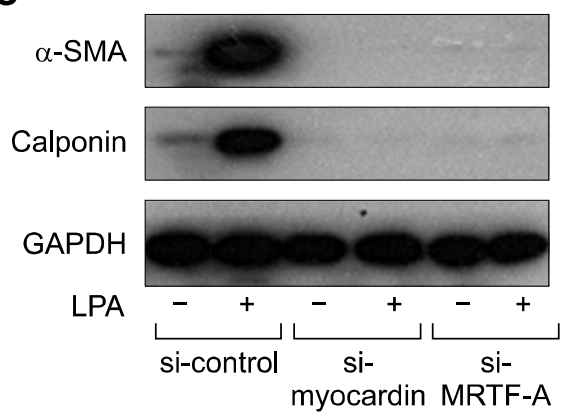

E

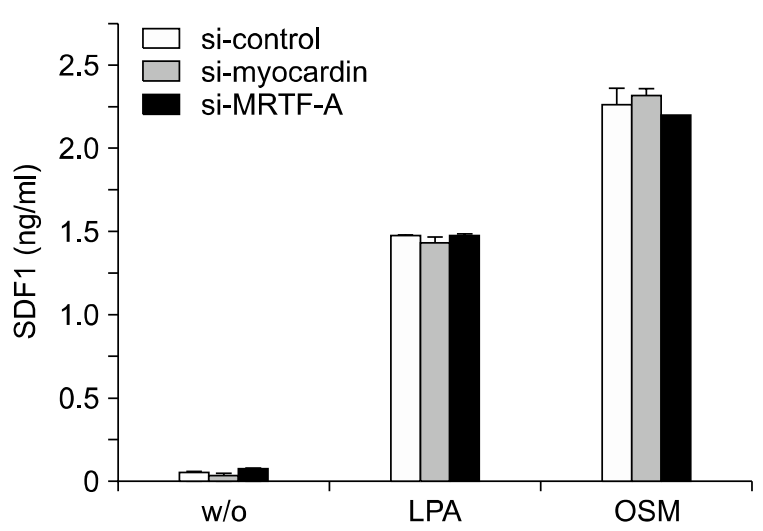

Figure 4. Role of myocarin and MRTF-A in the LPA-induced expression of $\alpha$-SMA, VEGF and SDF-1. (A) hASCs were treated with $5 \mu M$ LPA or $1 \mathrm{ng} / \mathrm{ml}$ TGF- $\beta 1$ for the indicated times. (B) hASCs were transfected with control siRNA (si-control), siRNAs specific for myocardin (si-myocardin) or MRTF-A (si-MRTF-A). The mRNA levels of $\alpha$-SMA, $h 1$-calponin, myocardin, MRTF-A, and GAPDH were determined by RT-PCR. (C) The siRNA-transfected hASCs were treated with $5 \mu \mathrm{M}$ LPA or vehicles for 4 days and the expression levels of $\alpha$-SMA and GAPDH were determined by Western blotting. Representatives of three independent experiments are shown. ( $D$ and $E$ ). The siRNA-transfected hASCs were treated with serum-free media containing 5 $\mu \mathrm{M}$ LPA or $10 \mathrm{ng} / \mathrm{ml}$ OSM for $48 \mathrm{~h}$ and the CM from hASCs was subjected to ELISA for analysis of VEGF (D) and SDF-1 (E). Data represent mean \pm S.D. $(n=4) .{ }^{*}, P<0.01$ by two-way ANOVA and Scheffe's post hoc test.

using sh-LPA 1 lentivirus. LPA- and cancer CM-induced secretion of VEGF and SDF-1 was abrogated by shRNA-mediated silencing of endogenous LPA $_{1}$ (Figures $2 \mathrm{G}$ and $2 \mathrm{H}$ ). However, OSM-induced secretion of SDF-1 and VEGF was not affected by depletion of $\mathrm{LPA}_{1}$ expression (Figures $2 \mathrm{G}$ and $2 \mathrm{H}$ ). These results suggest that CM from OVCAR3 or SKOV3 cells induces expre- ssion of $\alpha$-SMA, VEGF, and SDF-1 through a LPA-LPA 1 -dependent mechanism.

\section{Involvement of $\mathrm{LPA}_{1}$ in the cancer CM stimulation of hASCs-mediated paracrine function on endothelial tube formation}

To explore whether activation of $L P A_{1}$ is required 
A

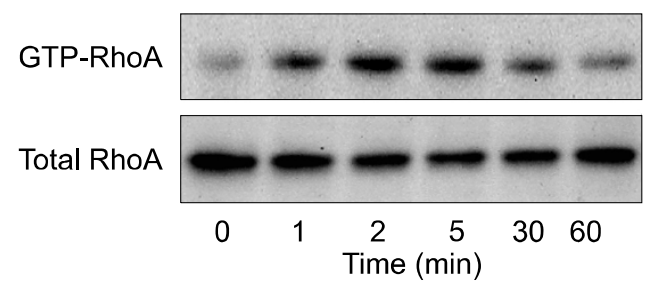

C

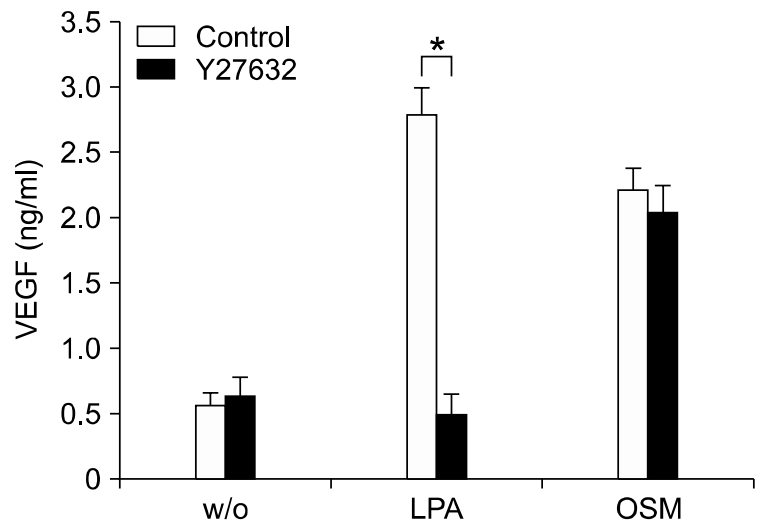

B

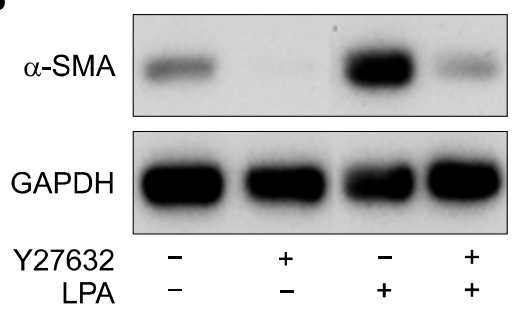

D

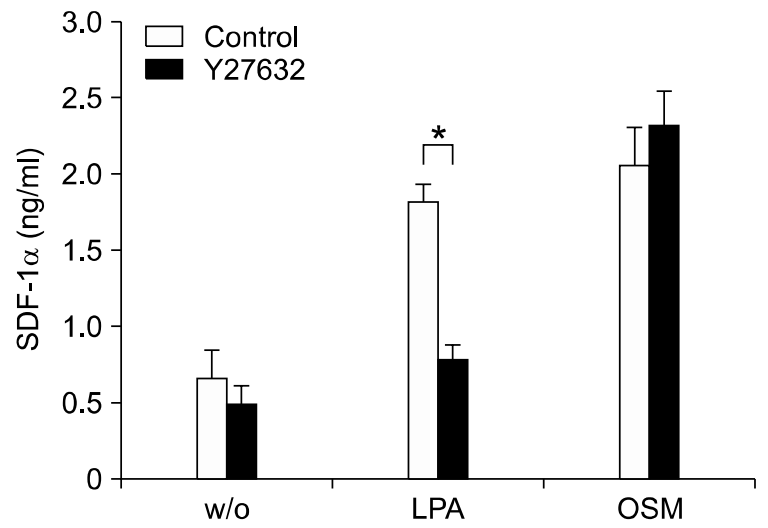

Figure 5. Role of RhoA-Rho kinase-dependent pathway in the LPA-induced expression of $\alpha$-SMA, VEGF and SDF-1. (A) Serum-starved hASCs were treated with $5 \mu \mathrm{M}$ LPA for the indicated time periods. The amounts of RhoA in the whole cell lysates (total RhoA) or the GTP-bound RhoA precipitated from the lysates were revealed by Western blotting using anti-RhoA antibody. (B) Serum-starved hASCs were treated with $5 \mu M$ LPA in the absence or presence of $10 \mu \mathrm{M}$ Y27632 for 4 days. The expression levels of $\alpha$-SMA and GAPDH were determined by Western blotting. Representative data from three independent experiments are shown. (C and D) hASCs were treated with serum-free medium containing $5 \mu \mathrm{M} \mathrm{LPA} \mathrm{or} 10 \mathrm{ng} / \mathrm{ml}$ OSM in the absence or presence of $10 \mu \mathrm{M}$ Y27632 for $48 \mathrm{~h}$ and the CM from hASCs was subjected to ELISA for analysis of VEGF (C) and SDF-1 (D). Data represent mean \pm S.D. $(n=4) .{ }^{*}, P<0.01$ by two-way ANOVA and Scheffe's post hoc test.

for the hASC-mediated stimulation of anigogenesis, hASCs were infected with sh-control or sh-LPA ${ }_{1}$ lentivirus and then treated with SKOV3 CM or $5 \mu \mathrm{M}$ LPA for collection of SKOV3 CM-hASC CM or LPA-hASC CM. As shown in Figure 3, SKOV3 CM-hASC CM or LPA-hASC CM, which were derived from sh-control-infected cells, stimulated endothelial tube formation, whereas those

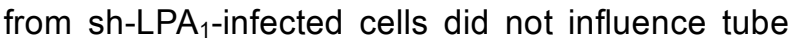
formation. These results suggest that LPA-LPA ${ }_{1}$ signaling pathway plays a pivotal role in the paracrine stimulation of hASC on endothelial tube formation in response to cancer $\mathrm{CM}$.

\section{Role of myocardin and MRTF in LPA-induced expression of $\alpha$-SMA, VEGF, and SDF-1}

Recent reports suggest that the transcription factor SRF and its cofactors (myocardin, MRTF-A, and MRTF-B) regulate expression of $\alpha$-SMA (Owens et al., 2004; Pipes et al., 2006; Parmacek, 2007). We have reported that TGF- $\beta 1$ and sphingosylpho- sphorylcholine induces expression of $\alpha$-SMA through a myocardin-dependent mechanism (Jeon et al., 2006). Furthermore, we demonstrated involvement of MRTF-A in the sphingosylphosphorylcholine-induced $\alpha$-SMA expression (Jeon et al., 2008b). To explore the effects of LPA on the expression of myocardin and MRTF-A, we measured the mRNA levels of myocardin and MRTF-A after LPA treatment. As shown in Figure 4A, the expression levels of myocardin and MRTF-A were increased after treatment of hASCs with LPA or TGF- $\beta 1$, suggesting a possible role of myocardin and MRTF-A in the LPA-induced $\alpha$-SMA expression. We next examined the involvement of myocardin and MRTF-A in the LPA-stimulated $\alpha$-SMA expression using siRNA-mediated gene silencing. As shown in Figure 4B, si-myocardin and si-MRTF-A specifically down-regulated the mRNA levels of myocardin and MRTF-A, respectively. Furthermore, si-myocardin and si-MRTF-A abrogated the LPA-induced $\alpha$-SMA expression (Figure 4C). These results suggest that both myocardin and MRTF-A play a key role in 
A

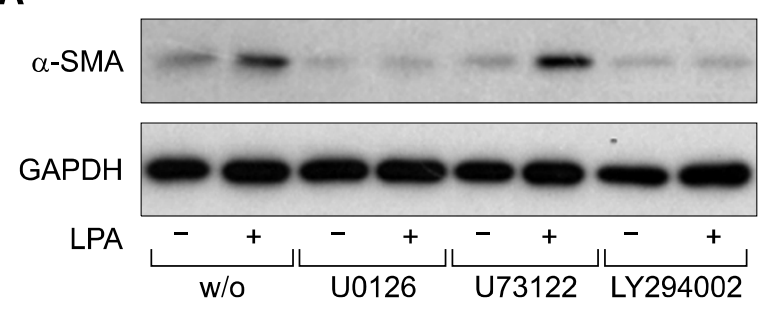

B

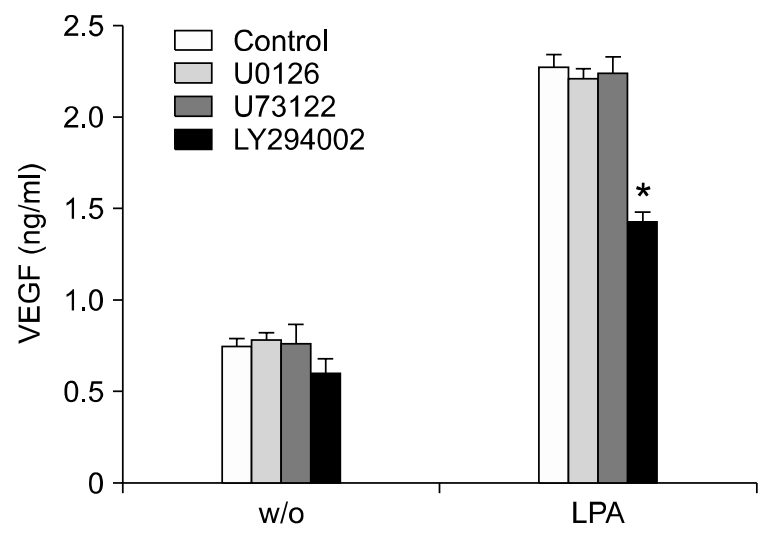

LPA-induced expression of $\alpha$-SMA in hASCs.

To explore whether myocardin and MRTF-A are involved in the LPA-induced expression of SDF-1 and VEGF, we determined the effects of siRNA-mediated silencing of myocardin and MRTF-A on the secreted levels of SDF-1 and VEGF. As shown in Figures 4D and 4E, expression of VEGF and SDF-1, which were induced by LPA or OSM, was not abrogated by siRNA-mediated silencing of endogenous myocardin or MRTF-A. These results suggest that myocardin and MRTF-A play a key role in the LPA-induced expression of $\alpha-S M A$, but not VEGF and SDF-1.

\section{Role of RhoA-Rho kinase-dependent pathway in LPA-induced expression of $\alpha$-SMA, SDF-1, and VEGF}

Accumulating evidence suggests that RhoA-mediated rearrangement of actin cytoskeleton plays a pivotal role in the expression of $\alpha$-SMA (Cen et al., 2004). LPA regulates the actin cytoskeleton through a RhoA-dependent mechanism (Anliker and Chun, 2004; Moolenaar et al., 2004). To explore whether LPA can activate RhoA in hASCs, we treated the cells with LPA and measured the resulting GTP-loaded RhoA levels. As shown in Figure 5A, GTP-RhoA was increased as early as 1 min following LPA treatment, decreasing to basal
Figure 6. Signaling pathways involved in the LPA-induced expression of $\alpha-S M A, V E G F$, and SDF-1. (A) hASCs were treated with $5 \mu \mathrm{M}$ LPA or vehicles in the absence or presence of $10 \mu \mathrm{M} \cup 0126,2.5 \mu \mathrm{M}$ U73122, $10 \mu \mathrm{M}$ LY294002 for 4 days and the expression levels of $\alpha$-SMA and GAPDH were determined by Western blotting. (B and C) hASCs were treated with $5 \mu \mathrm{M}$ LPA or vehicles in the absence or presence of $10 \mu \mathrm{M}$ U0126, $2.5 \mu \mathrm{M}$ U73122, $10 \mu \mathrm{M}$ LY294002 for 2 days and the conditioned medium was subjected to ELISA for analysis of VEGF (B) and SDF-1 (C). Data represent mean \pm S.D. $(n=4) .{ }^{*}, P<0.01$ by two-way ANOVA and Scheffe's post hoc test.

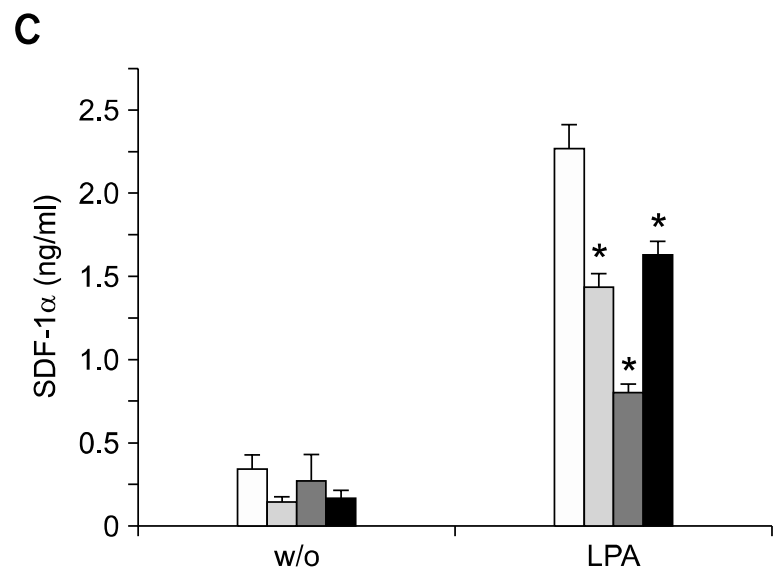

levels by $60 \mathrm{~min}$. To explore whether RhoA elicits LPA-induced $\alpha$-SMA expression through a mechanism involving Rho kinase, one of its major downstream targets, we examined the effect of Y27632, a Rho kinase-specific inhibitor, on LPA induction of $\alpha$-SMA expression. As shown in Figure 5B, pretreating cells with Y27632 abrogated their LPA-induced expression of $\alpha$-SMA. To explore the involvement of Rho kinase in LPA-induced expression of SDF-1 and VEGF, we next determined the secreted levels of SDF-1 and VEGF using ELISA analysis. Y27632 blocked the LPA-induced secretion of VEGF and SDF-1 from hASCs, in contrast to the non-significant impact on the OSM-stimulated secretion of VEGF and SDF-1 (Figures $5 \mathrm{C}$ and $5 \mathrm{D}$ ). These results indicate that Rho kinase pathway plays a key role in the LPA-induced expression of $\alpha$-SMA and secretion of SDF-1 and VEGF in hASCs.

\section{Signaling pathways implicated in LPA-induced expression of $\alpha$-SMA, SDF-1, and VEGF}

In addition to the RhoA pathway, LPA has been shown to activate diverse signaling pathways including PLC, phosphoinositide-3-kinase (PI3K), and ERK (Anliker and Chun, 2004; Moolenaar et al., 2004). In order to explore the involvement of 
these signaling enzymes in the LPA-induced $\alpha$-SMA expression, we examined the effects of specific inhibitors against these signaling enzymes on the expression levels of $\alpha$-SMA. As shown in Figure 6A, LPA-induced $\alpha$-SMA expression was abrogated by the MEK-ERK inhibitor U0126 and the phosphoinositide-3-kinase inhibitor LY294002. However, the PLC inhibitor U73122 did not influence the LPA-stimulated $\alpha$-SMA expression. These results indicate that phosphoinositide-3-kinase and ERK are involved in the LPA-stimulated $\alpha-S M A$ expression. To determine the involvement of PLC, PI3K, and ERK in the LPA-induced secretion of VEGF and SDF-1, we next examined the effects of the enzyme inhibitors on the secreted levels of VEGF and SDF-1. As shown in Figure 6B, LPA-induced VEGF secretion was inhibited by LY294002, but not by U73122 or U0126, whereas LPA-induced SDF-1 secretion was markedly attenuated by U0126, U73122, and LY294002 (Figure 6C). These results suggest that LPA regulates expression of $\alpha-S M A$, VEGF, and SDF-1 through different signaling pathways involving PLC, $\mathrm{PI} 3 \mathrm{~K}$, and ERK.

\section{Discussion}

Increasing evidence suggests that VEGF and SDF-1 are expressed in not only tumor cells but also CAFs within solid tumors (Allinen et al., 2004; Orimo et al., 2005; Hofmeister et al., 2008). The expression of VEGF was found to be predominantly induced in the $\alpha$-SMA-positive CAFs in a gastric cancer mouse model (Guo et al., 2008) and in a xenograft ovarian cancer model (Spaeth et al., 2009). It has been reported that stromal expression of VEGF is correlated with tumor grade and microvessel density in mammary phyllodes tumors (Tse et al., 2004). In addition, SDF-1 expression is significantly up-regulated in CAFs isolated from breast cancer specimens compared to normal breast fibroblasts (Orimo et al., 2005). CAF-derived SDF-1 not only increases carcinoma cell growth directly through the CXCR4 receptor displayed on tumor cells, but also serves to recruit endothelial progenitor cells into tumors, thereby stimulating neoangiogenesis (Orimo and Weinberg, 2006). CM from tumor cells promotes the production of SDF-1 in MSCs (Menon et al., 2007; Mishra et al., 2008). Furthermore, hASCs stimulate tumorigenesis of a murine breast cancer $4 \mathrm{~T} 1$ cell line in a xenograft transplantation model, and breast cancer cells induce secretion of SDF-1 from hASCs (Muehlberg et al., 2009). In spite of the functional importance of CAF-derived VEGF and SDF-1 in tumorigenesis, the molecular mechanisms associated with the expression of pro-angiogenic factors in CAFs have not been clarified. In the present study, we demonstrate that LPA mediates the expression of VEGF and SDF-1 induced by CM from ovarian cancer cells. LPA stimulates VEGF secretion from MSCs in vitro and transplantation of LPA-treated MSCs enhances capillary density in ischemic myocardium (Liu et al., 2009). Therefore, it is likely that LPA-induced secretion of VEGF and SDF-1 from MSCs may play a key role in the tumorigenesis and angiogenesis.

We demonstrated here that LPA-induced VEGF secretion was dependent on Rho kinase and PI3K in hASCs, while LPA-induced SDF-1 secretion was mediated by Rho kinase, ERK, PLC, and PI3K. LPA stimulates VEGF expression in ovarian cancer cells and colon carcinoma cells in vitro ( $\mathrm{Hu}$ et al., 2001; Shida et al., 2003). In ovarian cancer cells, LPA induction of VEGF expression is dependent on PI3K and ERK pathways (Lee et al., 2006). LPA stimulates VEGF expression through activation of c-Myc and SP-1 transcription factors in ovarian cancer cells, and $\mathrm{G}_{12 / 13}-\mathrm{RhoA}-\mathrm{Rho}$ kinase-dependent pathway is required for activation of c-Myc (Song et al., 2009). These results suggest that multiple signaling pathways may regulate differentially the LPA-induced expression of VEGF and SDF-1 depending on cell types.

Presently, LPA treatment increased expression of MRTF-A and myocardin, and siRNA-mediated depletion of myocardin and MRTF-A abrogated the LPA-stimulated expression of $\alpha$-SMA. It is well-established that expression of most SMC-specific differentiation marker genes including $\alpha$-SMA relies on the SRF/myocardin-dependent pathway (Miano, 2003; Wang and Olson, 2004). In addition, mouse embryos lacking myocardin die during the early stage of smooth muscle development; they fail to express multiple smooth muscle marker genes in embryonic dorsal aorta and other vascular structures (Li et al., 2003). Forced expression of myocardin is sufficient to induce the expression of smooth muscle-specific genes in human MSCs (van Tuyn et al., 2005; Ventura, 2005), and dominant-negative myocardin mutants and myocardin-specific siRNAs inhibit SMC differentiation marker gene expression in a variety of smooth muscle cell types, including the primary rat aortic SMC, A7r5, Pac1, and A10 SMC lines (Du et al., 2003; Wang et al., 2003; Yoshida et al., 2003). We have previously reported that LPA induces $\alpha$-SMA expression via an autocrine TGF- $\beta 1$ signaling pathway in part (Jeon et al., 2008a) and that myocardin mediates the TGF- $\beta$-dependent expression of $\alpha$-SMA (Jeon et al., 2006). Taken together, 
these results support the notion that myocardin plays a key role in the LPA-induced $\alpha$-SMA expression. Furthermore, we have previously reported that RhoA-dependent activation of MRTF-A mediates $\alpha$-SMA expression induced by sphingosylphosphorylcholine treatment in hASCs (Jeon et al., 2008b). It has been amply documented that LPA induces RhoA activation via $\mathrm{G}_{12 / 13}$-dependent mechanism, with the RhoA stimulating the downstream Rho kinase (Anliker and Chun, 2004; Moolenaar et al., 2004; Meyer zu and Jakobs, 2007). Activation of the RhoA-Rho kinase pathway promotes the assembly of monomeric G-actin into F-actin filaments (Sotiropoulos et al., 1999; Copeland and Treisman, 2002) and actin polymerization results in the translocation of MRTF-A from the cytoplasm to the nucleus (Cen et al., 2003; Miralles et al., 2003; Du et al., 2004), suggesting that Rho kinase-dependent activation of MRTF-A may be associated with the LPA-stimulated $\alpha$-SMA expression. Taken together, these results imply that myocardin and MRTF-A may play a key role in the differentiation of MSCs to $\alpha$-SMA-positive CAFs.

The importance of reactive tumor microenvironments in tumorigenesis and metastasis is increasingly appreciated. LPA is an essential microenvironmental factor in ovarian cancer, and high levels of LPA in the ascitic fluid and sera of patients have been correlated with poor prognosis of the disease (Xu et al., 1995; 1998). Moreover, LPA has been shown to be produced by ovarian cancer cells (Shen et al., 1998; Eder et al., 2000; Luquain et al., 2003; Sengupta et al., 2003). In the present study, we determined the LPA levels in ovarian cancer $\mathrm{CM}$ and the concentrations of LPA in OVCAR3 CM and SKOV3 CM were 1,193 \pm 245 and $545 \pm 72$ $\mathrm{nM}$, respectively. Furthermore, cancer $\mathrm{CM}$ induced expression of phenotypic and functional markers of CAFs ( $\alpha$-SMA, VEGF, and SDF-1) through Ki16425-sensitive mechanism. Although Ki16425 has been shown to inhibit both LPA 1 and $L^{2} A_{3}$ (Ohta et al., 2003), we have reported that LPA1 is a major LPA receptor isoform expressed in mesenchymal stem cells and that $\mathrm{LPA}_{1}$ plays a key role in the LPA-induced cellular responses, such as $\alpha$-SMA expression and cell migration (Jeon et al., 2008a; Lee et al., 2008; Song et al., 2010). Taken together with the finding that shRNA-mediated silencing of $\mathrm{LPA}_{1}$ completely abrogated the LPA-induced $\alpha$-SMA expression, these results lead us to suggest that cancer-derived LPA promotes differentiation of tissue-resident MSCs toward CAFs in tumor microenvironment and that LPA may be a useful target for therapy of tumorigenesis and tumor angiogenesis.

\section{Methods}

\section{Materials}

$\alpha$-Minimum essential medium ( $\alpha$-MEM), trypsin, and FBS were purchased from Invitrogen (Carlsbad, CA). Anti-GAPDH antibody was purchased from Millipore (Billerica, MA). Anti-RhoA antibody was from Santa Cruz Biotechnology (Santa Cruz, CA). LY294002, Y27632, U0126, and U73122 were purchased from BIOMOL (Plymouth Meeting, PA). 1-Oleoyl-sn-glycero-3-phosphate (1-oleoyl-LPA), Ki16425, and anti- $\alpha$-SMA antibody were from Sigma-Aldrich (St. Louis, MO). Human VEGF Duoset (DY293B), human SDF-1 Duoset (DY350), human recombinant oncostatin $M$, and human recombinant TGF- $\beta 1$ were purchased from R\&D Systems (Minneapolis, $M N)$. Matrigel was purchased from BD Biosciences (Franklin Lakes, NJ). Culture plates were purchased from Nunc (Roskilde, Denmark). Peroxidase-labeled secondary antibodies and Enhanced Chemiluminescence Western blotting system were from Amersham Biosciences (Piscataway, NJ).

\section{Cell culture}

Subcutaneous adipose tissue was obtained from elective surgeries with the patient's consent as approved by the Institution Review Board of Pusan National University Hospital. For isolation of hASCs, adipose tissues were washed at least three times with sterile PBS and treated with an equal volume of collagenase type I suspension (1 $\mathrm{g} /$ liter of HBSS buffer with $1 \%$ bovine serum albumin) for $60 \mathrm{~min}$ at $37^{\circ} \mathrm{C}$ with intermittent shaking. The floating adipocytes were separated from the stromal-vascular fraction by centrifugation at $300 \times g$ for $5 \mathrm{~min}$. The cell pellet was resuspended in $\alpha$-MEM supplemented with $10 \%$ FBS, $100 \mathrm{U} / \mathrm{ml}$ penicillin, and $100 \mu \mathrm{g} / \mathrm{ml}$ streptomycin, and cells were plated in tissue culture dishes at 3,500 cells $/ \mathrm{cm}^{2}$. The primary hASCs were cultured for 4-5 days until they reached confluence and were defined as passage " 0 ". The passage number of hASCs used in these experiments was $3-10$.

\section{Tube formation assay}

Human umbilical vein endothelial cells (HUVECs, Lonza, Basel, Switzerland) were maintained in a $37^{\circ} \mathrm{C}, 5 \% \mathrm{CO}_{2}$ humidified environmental chamber. The cells were grown in an Endothelial Growth Medium-2 bullet kit (Lonza) according to the manufacturer's instructions. For tube formation assay of HUVECs, aliquots $(250 \mu \mathrm{l})$ of growth factor-reduced Matrigel (10 $\mathrm{mg}$ protein $/ \mathrm{ml}$ ) were added into 24 -well culture dishes and polymerized for $30 \mathrm{~min}$ at $37^{\circ} \mathrm{C}$. HUVECs were trypsinized, resuspended in EGM-2 basal medium supplanted with $1 \%$ FBS, and plated onto a layer of Matrigel at a density of $1 \times 10^{5}$ cells/well. The cells were then exposed to cancer $\mathrm{CM}$ or culture supernatants from cancer CM-pretreated hASCs. After incubation of the Matrigel cultures at $37^{\circ} \mathrm{C}$ for $12 \mathrm{~h}$, the cultures were photographed using an inverted microscope with a digital camera. 


\section{Enzyme-linked immunosorbent assay (ELISA)}

Commercially available sandwich ELISA kits were used to evaluate the protein levels of SDF-1 and VEGF in the CM derived from hASCs. In brief, cells were seeded in wells of a 24-well culture plate at a density of $1 \times 10^{4}$ cells/well and cultured for $48 \mathrm{~h}$ to confluence in the growth medium. After treatment of the cells with serum-free medium supplemented with appropriate reagents, CM was collected and centrifuged at $15,000 \times g$ for $30 \mathrm{~min}$ to remove particulates. ELISA of the CM was carried out according to the manufacturer's protocol. The absorbance $(450 \mathrm{~nm})$ for each sample was analyzed by an ELISA reader and was interpolated with a standard curve.

\section{Western blot analysis}

Serum-starved hASCs were treated with appropriate conditions, washed with ice-cold PBS, and then lysed in lysis buffer (20 mM Tris-HCl, 1 mM EGTA, 1 mM EDTA, 10 $\mathrm{mM} \mathrm{NaCl}, 0.1 \mathrm{mM}$ PMSF, $1 \mathrm{mM} \mathrm{Na}_{3} \mathrm{VO}_{4}, 30 \mathrm{mM}$ sodium pyrophosphate, $25 \mathrm{mM} \beta$-glycerol phosphate, $1 \%$ Triton $X-100, \mathrm{pH} 7.4)$. Lysates were resolved by SDS-PAGE, transferred onto a nitrocellulose membrane, and then stained with $0.1 \%$ Ponceau S solution (Sigma-Aldrich). After blocking with $5 \%$ nonfat milk, the membranes were immunoblotted with various antibodies, and the bound antibodies were visualized with HRP-conjugated secondary antibodies using the Enhanced Chemiluminescence Western blotting system (Amersham Biosciences).

\section{RhoA activation assay}

A commercially available pull-down assay kit (Rho activation assay kit, Upstate Biotechnology, Lake Placid, NY) was used to measure the effect of LPA on Rho activity in hASCs. The cells were washed twice with $\alpha$-MEM and incubated in fresh modified $\alpha$-MEM without serum for $24 \mathrm{~h}$. After treatment of the cells with LPA for the indicated times, the cells were lysed, and the activated Rho pull-down assay was performed according to the manufacturer's protocol. Protein concentration was determined prior to pull-down assay to equalize the total protein concentration of each treatment group.

\section{Preparation of CM}

Cells were seeded on $100 \mathrm{~mm}$-diameter cell culture dishes and cultured in growth medium until reaching confluence. The cells were briefly rinsed twice with PBS, and then incubated with $10 \mathrm{ml}$ of fresh, serum-free $\alpha$-MEM for $48 \mathrm{~h}$ before collection of medium. The CM was centrifuged at 2,000 rpm for $10 \mathrm{~min}$ to remove cell debris, filtrated using $0.45-\mu \mathrm{m}$ Millipore Ultrafree centrifugal filters (Millipore, Bedford, MA), and stored at $-70^{\circ} \mathrm{C}$ for subsequent use.

\section{Measurement of LPA concentration in CM}

The LPA level was determined by a commercially available LPA assay kit (Universal LPA assay kit, Echelon Biosciences, Salt Lake City, UT) according to the manufacturer's instructions. In brief, each well of coated microtiter plate was blocked by adding blocking solution and washed with ice-cold PBS four times. Samples or LPA standards were mixed with biotinylated anti-LPA antibody and the mixtures $(100 \mu \mathrm{l} /$ well $)$ were transferred to the microtiter plate. After incubation for $1 \mathrm{~h}$ at $4^{\circ} \mathrm{C}$, the plate was washed with ice-cold PBS and streptavidin HRP solution was added to each well of the microtiter plate. After $1 \mathrm{~h}$, the plate was washed, and then tetramethylbenzidine substrate were added to each well and incubated for $4 \mathrm{~min}$ at room temperature. $\mathrm{H}_{2} \mathrm{SO}_{4}(1 \mathrm{~N})$ was added to each well to stop the reaction and the absorbance of the solution at $450 \mathrm{~nm}$ was determined by using a PowerWavex microplate spectrophotometer (Bio-Tek Instruments, Winooski, VT).

\section{RT-PCR analysis}

Cells were treated as indicated, and total cellular RNA was extracted by the Trizol method (Invitrogen). For RT-PCR analysis, aliquots of $2 \mu \mathrm{g}$ RNA were subjected to cDNA synthesis with $200 \mathrm{U}$ of M-MLV reverse transcriptase (Invitrogen) and $0.5 \mu \mathrm{g}$ of oligo (dT) 15 primer (Promega, Madison, $\mathrm{WI})$. The cDNA in $2 \mu \mathrm{l}$ of the reaction mixture was amplified with $0.5 \mathrm{U}$ of GoTaq DNA polymerase (Promega) and $10 \mathrm{pmol}$ each of sense and antisense primers as follows: GAPDH 5'-TCCATGACAACTTTGG'TATCG-3' (sense), 5'-TGTAGCCAAATTCGTTGTCA-3'

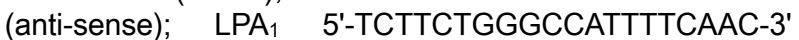
(sense), 5'-TGCCTRAAGGTGGCGCTCAT-3' (antisense); myocardin 5'-TCCAACGGCTTCTACCACTT-3' (sense), 5'-CACCTTCTGCTTCTCCACCA-3' (anti-sense); MRTF-A 5'-ACCGTGACCAATAAGAATGC-3' (sense), 5'-CATCTGCTGGCTTGAGGAAC-3' (anti-sense); $\alpha$-SMA 5'-CCTGACTGAGCGTGGCTATT-3' (sense), 5'-GATGAAGGATGGCTGGAACA-3' (anti-sense); h1-calponin 5'-GCCCAGAAGTATGACCACCA-3' (sense), 5'-TGATGAAGTTGCCGATGTTC-3' (anti-sense). The thermal cycle profile was as follows: denaturation for $30 \mathrm{~s}$ at $95^{\circ} \mathrm{C}$, annealing for $45 \mathrm{~s}$ at $52-58^{\circ} \mathrm{C}$ depending on the primers used, and extension for $45 \mathrm{~s}$ at $72^{\circ} \mathrm{C}$. For semi-quantitative assessment of expression levels, each PCR reaction was carried out for 30 cycles. PCR products were size fractionated on $1.2 \%$ ethidium bromide/agarose gel and quantified under ultraviolet transillumination.

\section{Transfection with siRNA}

For siRNA experiments, hASCs were plated on 60 $\mathrm{mm}$-diameter dishes. At $70 \%$ confluence, the cells were transfected with appropriate siRNAs using Lipofectamine ${ }^{T M}$ 2000 reagent according to manufacturer's instructions (Invitrogen). LPA 1 siRNA duplexes were synthesized, desalted, and purified by Samchully Pharm. Co. Ltd. (Siheung, GyeongGi, Korea) as follows: LPA 1 5'-GGACUUGGAAUCACUGUUUUU-3' (sense) and 5'-AAACAGUGAUUCCAAGUCCUU-3'. Myocardin siRNA, MRTF-A siRNA, and nonspecific control siRNA were purchased from Dharmacon (Lafayette, CO). Briefly, LipofectamineTM 2000 reagent was incubated with serum-free medium for $10 \mathrm{~min}$ and respective siRNAs were then added into the mixtures. After incubation for $15 \mathrm{~min}$ at room temperature, the mixtures were diluted with serum-free medium and 
added to each well to a final concentration of $100 \mathrm{nM}$. After incubation of hASCs with siRNAs for $6 \mathrm{~h}$, the cells were cultured in growth medium for $24 \mathrm{~h}$, and the expression levels of target genes were determined by Western blotting or RT-PCR analysis.

\section{Short hairpin RNA (shRNA) lentivirus-mediated depletion of endogenous $\mathrm{LPA}_{1}$}

pLKO.1-puro lentiviral vectors expressing LPA $_{1}$ shRNA (TRCN0000011368) or nontarget control shRNA (SHC002) were purchased from Sigma-Aldrich. The functional sequence in the $\mathrm{LPA}_{1}$ shRNA lentiviral vector is "CCGGCCTTCTGAAGACTGTGGTCATCTCGAGATGACC ACAGTCTTCAGAAGGTTTTT" to target the LPA $_{1}$ gene sequence (CCTTCTGAAGACTGTGGTCAT). To generate lentiviral particles, HEK293FT cells were co-transfected with the shRNA lentiviral plasmid (pLKO.1-puro) and ViraPower Lentiviral packaging mix (pLP1, pLP2, pLP-VSV-G; Invitrogen) using Lipofectamine 2000 (Invitrogen) and the culture supernatants containing lentivirus were harvested at $48 \mathrm{~h}$ after transfection. For lentiviral transduction, hASCs were treated with the shRNA-expressing lentivirus in the presence of $5 \mu \mathrm{g} / \mathrm{ml}$ polybrene (Sigma-Aldrich) and stable cell lines expressing shRNA were generated by selection with puromycin ( 5 $\mu \mathrm{g} / \mathrm{ml})$. To ensure shRNA-mediated silencing of $\mathrm{LPA}_{1}$ expression, the mRNA levels of LPA ${ }_{1}$ and GAPDH were determined by RT-PCR analysis.

\section{Statistical analyses}

The results of multiple observations are presented as mean \pm SE. Student's $t$ test were used to analyze differences between two groups. For multivariate data analysis, group differences were assessed with two-way ANOVA, followed by post hoc comparisons tested with Scheffes method.

\section{Acknowledgments}

This work was supported by the National R\&D Program for Cancer Control, Ministry of Health and Welfare, Republic of Korea (00000033 and 0920050).

\section{References}

Allinen M, Beroukhim R, Cai L, Brennan C, Lahti-Domenici J, Huang H, Porter D, Hu M, Chin L, Richardson A, Schnitt $\mathrm{S}$, Sellers WR, Polyak K. Molecular characterization of the tumor microenvironment in breast cancer. Cancer Cell 2004; 6:17-32

Anliker B, Chun J. Cell surface receptors in lysophospholipid signaling. Semin Cell Dev Biol 2004;15:457-65

Aoki J. Mechanisms of lysophosphatidic acid production. Semin Cell Dev Biol 2004;15:477-89

Barry FP, Murphy JM. Mesenchymal stem cells: clinical applications and biological characterization. Int J Biochem

\section{Cell Biol 2004;36:568-84}

Beckermann BM, Kallifatidis G, Groth A, Frommhold D, Apel A, Mattern J, Salnikov AV, Moldenhauer G, Wagner W, Diehlmann A, Saffrich R, Schubert M, Ho AD, Giese N, Buchler MW, Friess H, Buchler P, Herr I. VEGF expression by mesenchymal stem cells contributes to angiogenesis in pancreatic carcinoma. Br J Cancer 2008;99:622-31

Bhowmick NA, Neilson EG, Moses HL. Stromal fibroblasts in cancer initiation and progression. Nature 2004;432:332-7

Birgbauer E, Chun J. New developments in the biological functions of lysophospholipids. Cell Mol Life Sci 2006;63: 2695-701

Cen B, Selvaraj A, Burgess RC, Hitzler JK, Ma Z, Morris SW, Prywes R. Megakaryoblastic leukemia 1, a potent transcriptional coactivator for serum response factor (SRF), is required for serum induction of SRF target genes. Mol Cell Biol 2003;23:6597-608

Cen B, Selvaraj A, Prywes R. Myocardin/MKL family of SRF coactivators: key regulators of immediate early and muscle specific gene expression. J Cell Biochem 2004;93:74-82

Chen J, Kitchen CM, Streb JW, Miano JM. Myocardin: a component of a molecular switch for smooth muscle differentiation. J Mol Cell Cardiol 2002;34:1345-56

Copeland JW, Treisman R. The diaphanous-related formin mDia1 controls serum response factor activity through its effects on actin polymerization. Mol Biol Cell 2002;13: 4088-99

Crisan M, Yap S, Casteilla L, Chen CW, Corselli M, Park TS, Andriolo G, Sun B, Zheng B, Zhang L, Norotte C, Teng PN Traas J, Schugar R, Deasy BM, Badylak S, Buhring HJ, Giacobino JP, Lazzari L, Huard J, Peault B. A perivascular origin for mesenchymal stem cells in multiple human organs. Cell Stem Cell 2008;3:301-13

De Wever O, Mareel M. Role of tissue stroma in cancer cell invasion. J Pathol 2003;200:429-47

De Wever O, Demetter P, Mareel M, Bracke M. Stromal myofibroblasts are drivers of invasive cancer growth. Int J Cancer 2008;123:2229-38

Desmouliere A, Guyot C, Gabbiani G. The stroma reaction myofibroblast: a key player in the control of tumor cell behavior. Int J Dev Biol 2004;48:509-17

Du KL, Ip HS, Li J, Chen M, Dandre F, Yu W, Lu MM, Owens GK, Parmacek MS. Myocardin is a critical serum response factor cofactor in the transcriptional program regulating smooth muscle cell differentiation. Mol Cell Biol 2003; 23:2425-37

Du KL, Chen M, Li J, Lepore JJ, Mericko P, Parmacek MS. Megakaryoblastic leukemia factor-1 transduces cytoskeletal signals and induces smooth muscle cell differentiation from undifferentiated embryonic stem cells. J Biol Chem 2004; 279:17578-86

Eder AM, Sasagawa T, Mao M, Aoki J, Mills GB. Constitutive and lysophosphatidic acid (LPA)-induced LPA production: role of phospholipase $D$ and phospholipase A2. Clin Cancer Res 2000;6:2482-91 
Gaits F, Fourcade O, Le Balle F, Gueguen G, Gaige B, Gassama-Diagne A, Fauvel J, Salles JP, Mauco G, Simon MF, Chap H. Lysophosphatidic acid as a phospholipid mediator: pathways of synthesis. FEBS Lett 1997;410:54-8

Ganss R. Tumor stroma fosters neovascularization by recruitment of progenitor cells into the tumor bed. J Cell Mol Med 2006;10:857-65

Gomez-Lechon MJ. Oncostatin M: signal transduction and biological activity. Life Sci 1999;65:2019-30

Guo X, Oshima H, Kitmura T, Taketo MM, Oshima M. Stromal fibroblasts activated by tumor cells promote angiogenesis in mouse gastric cancer. J Biol Chem 2008;283:19864-71

Hall B, Andreeff M, Marini F. The participation of mesenchymal stem cells in tumor stroma formation and their application as targeted-gene delivery vehicles. Handb Exp Pharmacol 2007;180:263-83

Hofmeister V, Schrama D, Becker JC. Anti-cancer therapies targeting the tumor stroma. Cancer Immunol Immunother 2008;57:1-17

Hu YL, Tee MK, Goetzl EJ, Auersperg N, Mills GB, Ferrara $\mathrm{N}$, Jaffe RB. Lysophosphatidic acid induction of vascular endothelial growth factor expression in human ovarian cancer cells. J Natl Cancer Inst 2001;93:762-8

Jeon ES, Moon HJ, Lee MJ, Song HY, Kim YM, Bae YC, Jung JS, Kim JH. Sphingosylphosphorylcholine induces differentiation of human mesenchymal stem cells into smooth-muscle-like cells through a TGF- $\beta$-dependent mechanism. J Cell Sci 2006;119:4994-5005

Jeon ES, Moon HJ, Lee MJ, Song HY, Kim YM, Cho M, Suh DS, Yoon MS, Chang CL, Jung JS, Kim JH. Cancer-derived lysophosphatidic acid stimulates differentiation of human mesenchymal stem cells to myofibroblast-like cells. Stem Cells 2008a;26:789-97

Jeon ES, Park WS, Lee MJ, Kim YM, Han J, Kim JH. ARho kinase/myocardin-related transcription factor-A-dependent mechanism underlies the sphingosylphosphorylcholineinduced differentiation of mesenchymal stem cells into contractile smooth muscle cells. Circ Res 2008b;103:635-42

Karnoub AE, Dash AB, Vo AP, Sullivan A, Brooks MW, Bell GW, Richardson AL, Polyak K, Tubo R, Weinberg RA. Mesenchymal stem cells within tumour stroma promote breast cancer metastasis. Nature 2007;449:557-63

Lee J, Park SY, Lee EK, Park CG, Chung HC, Rha SY, Kim YK, Bae GU, Kim BK, Han JW, Lee HY. Activation of hypoxia-inducible factor-1alpha is necessary for lysophosphatidic acid-induced vascular endothelial growth factor expression. Clin Cancer Res 2006;12:6351-8

Lee MJ, Song HY, Kim MR, Sung SM, Jung JS, Kim JH. Oncostatin $\mathrm{M}$ stimulates expression of stromal-derived factor-1 in human mesenchymal stem cells. Int J Biochem Cell Biol 2007;39:650-9

Lee MJ, Jeon ES, Lee JS, Cho M, Suh DS, Chang CL, Kim $\mathrm{JH}$. Lysophosphatidic acid in malignant ascites stimulates migration of human mesenchymal stem cells. J Cell Biochem 2008;104:499-510

Li H, Fan X, Houghton J. Tumor microenvironment: The role of the tumor stroma in cancer. J Cell Biochem 2007;101: 805-15

Li S, Wang DZ, Wang Z, Richardson JA, Olson EN. The serum response factor coactivator myocardin is required for vascular smooth muscle development. Proc Natl Acad Sci USA 2003;100:9366-70

Liu X, Hou J, Shi L, Chen J, Sang J, Hu S, Cong X, Chen X. Lysophosphatidic acid protects mesenchymal stem cells against ischemia-induced apoptosis in vivo. Stem Cells Dev 2009;18:947-54

Luquain C, Singh A, Wang L, Natarajan V, Morris AJ. Role of phospholipase $D$ in agonist-stimulated lysophosphatidic acid synthesis by ovarian cancer cells. J Lipid Res 2003; 44:1963-75

Menon LG, Picinich S, Koneru R, Gao H, Lin SY, Koneru M, Mayer-Kuckuk P, Glod J, Banerjee D. Differential gene expression associated with migration of mesenchymal stem cells to conditioned medium from tumor cells or bone marrow cells. Stem Cells 2007;25:520-8

Meyer zu HD, Jakobs KH. Lysophospholipid receptors: signalling, pharmacology and regulation by lysophospholipid metabolism. Biochim Biophys Acta 2007;1768:923-40

Miano JM. Serum response factor: toggling between disparate programs of gene expression. J Mol Cell Cardiol 2003;35:577-93

Mills GB, Moolenaar WH. The emerging role of lysophosphatidic acid in cancer. Nat Rev Cancer 2003;3:582-91

Miralles F, Posern G, Zaromytidou AI, Treisman R. Actin dynamics control SRF activity by regulation of its coactivator MAL. Cell 2003;113:329-42

Mishra PJ, Mishra PJ, Humeniuk R, Medina DJ, Alexe G, Mesirov JP, Ganesan S, Glod JW, Banerjee D. Carcinoma-associated fibroblast-like differentiation of human mesenchymal stem cells. Cancer Res 2008;68:4331-9

Moolenaar WH, van Meeteren LA, Giepmans BN. The ins and outs of lysophosphatidic acid signaling. Bioessays 2004; 26:870-81

Muehlberg FL, Song YH, Krohn A, Pinilla SP, Droll LH, Leng $X$, Seidensticker M, Ricke J, Altman AM, Devarajan E, Liu W, Arlinghaus RB, Alt EU. Tissue-resident stem cells promote breast cancer growth and metastasis. Carcinogenesis 2009; 30:589-97

Murakami M, Shiraishi A, Tabata K, Fujita N. Identification of the orphan GPCR, P2Y(10) receptor as the sphingosine-1-phosphate and lysophosphatidic acid receptor. Biochem Biophys Res Commun 2008;371:707-12

Ohta H, Sato K, Murata N, Damirin A, Malchinkhuu E, Kon J, Kimura T, Tobo M, Yamazaki Y, Watanabe T, Yagi M, Sato M, Suzuki R, Murooka H, Sakai T, Nishitoba T, Im DS, Noch H, Tamoto K, Tomura H, Okajima F. Ki16425, a subtypeselective antagonist for EDG-family lysophosphatidic acid receptors. Mol Pharmacol 2003;64:994-1005

Olumi AF, Grossfeld GD, Hayward SW, Carroll PR, Tlsty TD, Cunha GR. Carcinoma-associated fibroblasts direct tumor progression of initiated human prostatic epithelium. Cancer Res 1999;59:5002-11 
Orimo A, Gupta PB, Sgroi DC, Arenzana-Seisdedos F, Delaunay T, Naeem R, Carey VJ, Richardson AL, Weinberg RA. Stromal fibroblasts present in invasive human breast carcinomas promote tumor growth and angiogenesis through elevated SDF-1/CXCL12 secretion. Cell 2005;121: 335-48

Orimo A, Weinberg RA. Stromal fibroblasts in cancer: a novel tumor-promoting cell type. Cell Cycle 2006;5:1597-601

Owens GK, Kumar MS, Wamhoff BR. Molecular regulation of vascular smooth muscle cell differentiation in development and disease. Physiol Rev 2004;84:767-801

Parmacek MS. Myocardin-related transcription factors: critical coactivators regulating cardiovascular development and adaptation. Circ Res 2007;100:633-44

Pipes GC, Creemers EE, Olson EN. The myocardin family of transcriptional coactivators: versatile regulators of cell growth, migration, and myogenesis. Genes Dev 2006;20: 1545-56

Pittenger MF, Mackay AM, Beck SC, Jaiswal RK, Douglas R, Mosca JD, Moorman MA, Simonetti DW, Craig S, Marshak DR. Multilineage potential of adult human mesenchymal stem cells. Science 1999;284:143-7

Prockop DJ. Marrow stromal cells as stem cells for nonhematopoietic tissues. Science 1997;276:71-4

Rega G, Kaun C, Demyanets S, Pfaffenberger S, Rychli K, Hohensinner PJ, Kastl SP, Speidl WS, Weiss TW, Breuss JM, Furnkranz A, Uhrin P, Zaujec J, Zilberfarb V, Frey M, Roehle R, Maurer G, Huber K, Wojta J. Vascular endothelial growth factor is induced by the inflammatory cytokines interleukin- 6 and oncostatin $\mathrm{m}$ in human adipose tissue in vitro and in murine adipose tissue in vivo. Arterioscler Thromb Vasc Biol 2007;27:1587-95

Sappino AP, Skalli O, Jackson B, Schurch W, Gabbiani G. Smooth-muscle differentiation in stromal cells of malignant and non-malignant breast tissues. Int $\mathrm{J}$ Cancer 1988;41: 707-12

Sengupta S, Xiao YJ, Xu Y. A novel laminin-induced LPA autocrine loop in the migration of ovarian cancer cells. FASEB J 2003;17:1570-2

Shen Z, Belinson J, Morton RE, Xu Y, Xu Y. Phorbol 12-myristate 13-acetate stimulates lysophosphatidic acid secretion from ovarian and cervical cancer cells but not from breast or leukemia cells. Gynecol Oncol 1998;71:364-8

Shida D, Kitayama J, Yamaguchi H, Okaji Y, Tsuno NH, Watanabe T, Takuwa Y, Nagawa H. Lysophosphatidic acid (LPA) enhances the metastatic potential of human colon carcinoma DLD1 cells through LPA1. Cancer Res 2003; 63:1706-11

Short B, Brouard N, Occhiodoro-Scott T, Ramakrishnan A, Simmons PJ. Mesenchymal stem cells. Arch Med Res 2003; 34:565-71

Song HY, Lee MJ, Kim MY, Kim KH, Lee IH, Shin SH, Lee JS, $\mathrm{Kim} \mathrm{JH}$. Lysophosphatidic acid mediates migration of human mesenchymal stem cells stimulated by synovial fluid of patients with rheumatoid arthritis. Biochim Biophys Acta 2010;1801:23-30
Song Y, Wu J, Oyesanya RA, Lee Z, Mukherjee A, Fang X. Sp-1 and c-Myc mediate lysophosphatidic acid-induced expression of vascular endothelial growth factor in ovarian cancer cells via a hypoxia-inducible factor-1-independent mechanism. Clin Cancer Res 2009;15:492-501

Sotiropoulos A, Gineitis D, Copeland J, Treisman R. Signal-regulated activation of serum response factor is mediated by changes in actin dynamics. Cell 1999;98: 159-69

Spaeth EL, Dembinski JL, Sasser AK, Watson K, Klopp A, Hall B, Andreeff M, Marini F. Mesenchymal stem cell transition to tumor-associated fibroblasts contributes to fibrovascular network expansion and tumor progression. PLoS ONE 2009;4:e4992

Tabata K, Baba K, Shiraishi A, Ito M, Fujita N. The orphan GPCR GPR87 was deorphanized and shown to be a Iysophosphatidic acid receptor. Biochem Biophys Res Commun 2007;363:861-6

Tse GM, Lui PC, Lee CS, Kung FY, Scolyer RA, Law BK, Lau TS, Karim R, Putti TC. Stromal expression of vascular endothelial growth factor correlates with tumor grade and microvessel density in mammary phyllodes tumors: a multicenter study of 185 cases. Hum Pathol 2004;35:1053-7 van Tuyn J, Knaan-Shanzer S, van de Watering MJ, de Graaf $M$, van der LA, Schalij MJ, van der Wall EE, de Vries AA, Atsma DE. Activation of cardiac and smooth muscle-specific genes in primary human cells after forced expression of human myocardin. Cardiovasc Res 2005;67:245-55

Ventura C. Forced myocardin expression primes cardiac and smooth muscle transcription patterning in human mesenchymal stem cells. Cardiovasc Res 2005;67:182-3

Wang Z, Wang DZ, Pipes GC, Olson EN. Myocardin is a master regulator of smooth muscle gene expression. Proc Natl Acad Sci USA 2003;100:7129-34

Wang DZ, Li S, Hockemeyer D, Sutherland L, Wang Z, Schratt G, Richardson JA, Nordheim A, Olson EN. Potentiation of serum response factor activity by a family of myocardin-related transcription factors. Proc Natl Acad Sci USA 2002;99:14855-60

Wang DZ, Olson EN. Control of smooth muscle development by the myocardin family of transcriptional coactivators. Curr Opin Genet Dev 2004;14:558-66.

Xu Y, Gaudette DC, Boynton JD, Frankel A, Fang XJ, Sharma A, Hurteau J, Casey G, Goodbody A, Mellors A. Characterization of an ovarian cancer activating factor in ascites from ovarian cancer patients. Clin Cancer Res 1995; 1:1223-32

Xu Y, Shen Z, Wiper DW, Wu M, Morton RE, Elson P, Kennedy AW, Belinson J, Markman M, Casey G. Lysophosphatidic acid as a potential biomarker for ovarian and other gynecologic cancers. JAMA 1998;280:719-23

Yoshida T, Sinha S, Dandre F, Wamhoff BR, Hoofnagle MH, Kremer BE, Wang DZ, Olson EN, Owens GK. Myocardin is a key regulator of CArG-dependent transcription of multiple smooth muscle marker genes. Circ Res 2003;92:856-64

Zhu W, Xu W, Jiang R, Qian H, Chen M, Hu J, Cao W, Han C, Chen $Y$. Mesenchymal stem cells derived from bone marrow favor tumor cell growth in vivo. Exp Mol Pathol 2006;80:267-74 